\title{
International Environmental Agreements for biodiversity conservation: a game-theoretic analysis
}

\author{
Irene Alvarado-Quesada ${ }^{1} \cdot$ Hans-Peter Weikard ${ }^{1}$
}

Accepted: 29 June 2017/Published online: 14 July 2017

(C) The Author(s) 2017. This article is an open access publication

\begin{abstract}
This paper contributes to the emerging literature on International Environmental Agreements with an analysis of key characteristics for biodiversity conservation. We study three features that are specific to an international conservation agreement: the existence of a natural upper bound of conservation in each country, the importance of local benefits, and the subadditivity of the global conservation function. We consider asymmetries in benefits and costs of conservation and, separately, in the upper bound of conservation in each country, and we examine the impacts of these features on coalition stability and on the effectiveness of biodiversity agreements. Results show that subadditivity of the global conservation function can lead to larger stable coalitions. The inclusion of a transfer scheme that might be implemented through, e.g., international trade of biodiversity credits, can have an impact on coalition composition and can improve conservation outcomes and the size of stable coalitions in certain ranges of the parameter space.
\end{abstract}

Keywords Coalition formation - Subadditivity $\cdot$ Local benefits $\cdot$ Hyperbolic cost functions · Asymmetric countries · Game theory

Electronic supplementary material The online version of this article (doi:10.1007/s10784-017-9368-7) contains supplementary material, which is available to authorized users.

Irene Alvarado-Quesada

irene.alvaradoq@gmail.com

Hans-Peter Weikard

hans-peter.weikard@wur.nl

1 Environmental Economics and Natural Resources Group, Wageningen University, P.O. Box 8130, 6700 EW Wageningen, The Netherlands 


\section{Introduction}

Management of global environmental resources is a difficult task because binding rules have to be agreed upon internationally but need to be implemented at the national level. A wide range of International Environmental Agreements (IEAs) have been negotiated to deal with particular environmental concerns. In particular, some of the main international agreements created to address biodiversity conservation are the Convention of Biological Diversity (CBD), the Convention on International Trade in Endangered Species of Wild Fauna and Flora (CITES), the Convention on the Conservation of Migratory Species of Wild Animals (CMS), the International Treaty on Plant Genetic Resources for Food and Agriculture (ITPGRFA), the Convention on Wetlands (also known as the Ramsar Convention), the World Heritage Convention (WHC) and the International Plant Protection Convention (IPPC). These treaties vary in scope and participation, but all of them have more than 120 signatories. Still, the effectiveness of such international treaties is a subject of concern (Young 2011) and biodiversity decline remains a key issue on the global environmental policy agenda.

Recent studies on the economic analysis of the formation and stability of IEAs (e.g., Finus 2001; Rubio and Ulph 2006; Pavlova and de Zeeuw 2013) have drawn on the seminal work of D’Aspremont et al. (1983), Carraro and Siniscalco (1993), Barrett (1994) and others. Most of this literature refers to the problem of global warming and IEAs for greenhouse gas (GHG) emissions control. With the notable exception of Winands et al. (2013), an analysis of the stability of an IEA for biodiversity conservation remains a gap in the literature.

Different characteristics distinguish the case of biodiversity conservation from the conventional emission abatement model. First, biodiversity is unevenly distributed among countries. Every country has a different biodiversity endowment that is finite, and consequently, effects of conservation efforts within a country are limited. Second, benefits from conservation are perceived differently at different scales (from local to global). Third, efforts of conservation should not be aggregated in an additive way as it is commonly done for emission abatement efforts in coalition formation models of climate change. Two areas of the same size can be very different in terms of biodiversity richness (as measured by a species count, for example). Therefore, they should not be valued equally. Furthermore, in order to measure biodiversity conservation, counting species in each country can lead to double counting of species in a global assessment. Additionally, in some cases spatial aspects such as habitat connectivity and minimum protected area size are considered as requirements for species conservation, implying that location of biodiversity does play an important role in the conservation game. Finally, the term "biodiversity" encompasses features inherent to public, club and private goods (Kaul 1999; Kumar 2010; Salles 2011). This combination of features is a challenge for efficient and sustainable management of biodiversity.

Given the specific features of biodiversity, international agreements for biodiversity conservation deserve some special attention. In terms of modeling, there are at least three characteristics that differentiate an IEA for biodiversity conservation from the emission abatement case. These characteristics are the focus of our paper.

The first feature is the existence of a natural upper bound of conservation in each country. For the case of GHGs, the maximum amount that a country can emit is not limited by nature but closely linked to its economic activities; in particular land use, transportation and industry. However, for the case of biodiversity conservation, the maximum amount of biodiversity that a country can preserve in its territory is limited. We assume that, as any 
country approaches its maximum level of conservation of biodiversity, each additional unit preserved is more costly. To represent an unlimited increase in marginal costs of conservation, we make use of hyperbolic cost functions in our model, instead of the often-used polynomial cost functions (e.g., quadratic functions) in models of climate agreements.

The second feature addresses the mismatch between the scales at which costs and benefits of biodiversity conservation take place. Costs of biodiversity conservation are local, but the benefits from conservation are perceived at different scales: local, regional and global. GHG reductions affect the global concentration of GHGs regardless of where the reductions take place, although the local impacts of these reductions can differ across countries. By contrast, biodiversity conservation is not a pure public good because local conservation measures can offer more immediate benefits at a local scale. Global benefits of biodiversity are those related to the public good dimension of biodiversity: one cannot prevent people from enjoying biodiversity (non-excludability) and a person's enjoyment of biodiversity does not deplete its availability to others (non-rivalry) (Alvarado-Quesada et al. 2014). Local benefits of biodiversity correspond to those benefits that are directly perceived from local biodiversity. For the purpose of this study, we use countries to represent the local dimension. For example, global forest conservation entails biodiversity benefits that are perceived at a global scale, regardless of the location where conservation efforts take place. However, in addition to those global benefits, forest conservation entails local benefits directly perceived by the inhabitants of the area where conservation occurs, such as timber and non-timber forest products, improvements in air quality and recreation benefits.

In the climate change literature attention has been drawn toward the disaggregation of benefits into public (primary) and private (secondary, local or ancillary) benefits (Rübbelke 2006; Pittel and Rübbelke 2008; Longo et al. 2012; Pittel and Rübbelke 2012; Finus and Rübbelke 2013). Local benefits have been found to be of significant size compared to global benefits, sometimes even larger (Pearce 2001). In the domain of biodiversity conservation, several studies refer to local (or secondary) benefits of conservation, such as Perrings and Gadgil (2003), Hein et al. (2006), Elmqvist (2012), Perrings and Halkos (2012), and Phelps et al. (2012). Winands et al. (2013) explicitly consider local benefits from biodiversity in a numerical model of an international biodiversity conservation agreement. We also consider local benefits of conservation in our model due to their important role in incentivizing participation in an international conservation agreement.

The third feature is the subadditivity of the global conservation function. Models of IEAs focus predominantly on emission abatement and usually define global abatement levels as the sum of the individual abatement levels of all countries. For the case of biodiversity, there is no standardized, generally accepted measurement of aggregate conservation levels. Therefore, we adopt a conceptual framework, developed by Weitzman (1998). In this framework conservation measurements are associated with sets of species or ecosystems. A diversity measure can, in principle, be built on the dissimilarity between species in a set. While such information will usually not be available, the framework can be made operational using a species count as an approximate measure of biodiversity. A species count is conceptually simple but still approximates biodiversity, although on the level of ecosystems (Weikard 2002, Proposition 1). Since it is plausible that two countries preserve some common species, we assume that global biodiversity conservation is a subadditive function of the aggregate of all countries' individual biodiversity conservation. An explicit aggregation model of biodiversity across regions has been developed by Punt et al. (2012). The model of this paper focuses on the conservation of biological diversity as an intrinsic policy goal. We consider it one of the main purposes of an IEA for biodiversity, 
and it is one of the main goals of the CBD (UN 1992), for example. However, our model is also compatible with an ecosystem services approach where conservation benefits are derived from a multitude of services; and our modeling approach can also address equitable sharing of benefits similar to Nagashima et al. (2009).

Finally, the assumption of symmetric countries frequently used in IEA models is often too restrictive: both costs and benefits of biodiversity conservation vary greatly between countries. Many countries that are well endowed in terms of biodiversity richness are among the poorest in terms of income (Swanson and Groom 2012). Moreover, the natural upper bound of conservation also differs among countries.

Asymmetry between countries has been a subject of study in the IEA literature. The assumption of symmetric countries has been relaxed by McGinty (2007) who illustrates by means of simulation exercises that IEAs with asymmetric countries can achieve substantial gains under an appropriate transfer scheme. Pavlova and de Zeeuw (2013) and Finus and McGinty (2015) study a model with two-sided asymmetry where countries differ in both emission-related benefits and environmental damages. They conclude that large coalitions can be stable under two-sided asymmetry, even when there are no transfers, but only if the asymmetries are sufficiently large. Furthermore, large coalitions perform better under asymmetry when transfers are allowed as compared to the symmetric case. Winands et al. (2013) focus on the role of asymmetries for the stability of biodiversity conservation agreements. Their numerical study reveals that in the absence of transfers, asymmetries among countries in terms of ecosystems and wealth reduce the size of a stable coalition as compared to a symmetric model specification. The inclusion of an optimal transfer scheme for the asymmetric case, on the other hand, stabilizes a grand coalition in a fourplayer game.

In order to account for the effect of asymmetry on coalition stability, our model includes asymmetry in two ways. First, we deal with two-sided asymmetry: both benefits and costs of conservation are different among countries. Each country then belongs to one of four distinct types of countries: high benefits-high costs (BC), high benefits-low costs (Bc), low benefits-high costs (bC) and low benefits-low costs (bc). Additionally, we include asymmetry among countries in the natural upper bound of conservation for three different scenarios.

Our model makes a novel contribution to the literature on international biodiversity conservation by including (1) a natural upper bound of conservation in each country combined with a hyperbolic cost function, (2) the inclusion of local benefits of conservation to represent the different scales at which biodiversity benefits are perceived and (3) the subadditivity feature of the global conservation function. For a more comprehensive analysis, we study these characteristics under the assumption of both symmetric and asymmetric countries and we also allow for transfers, possibly implemented by an international market for biodiversity credits. We focus on these features to examine how they impact coalition stability and the scope for effective biodiversity agreements in terms of conservation of biological diversity.

The paper is organized as follows. In Sect. 2 we study the impact of (1) hyperbolic costs, (2) local benefits of conservation, and (3) a subadditive function for the global conservation benefits on the size of stable coalitions. Section 3 combines these features but also considers asymmetric countries and allows for the inclusion of transfers. Section 4 discusses potential extensions of the model for future research. Section 5 summarizes the main findings and concludes. 


\section{IEA stability for biodiversity conservation with symmetric countries}

\subsection{The case of linear global and local benefits and hyperbolic cost functions}

To develop a model of an IEA for biodiversity conservation, we consider a two-stage cartel formation game with $n$ countries. In the first stage of the game, countries choose whether or not to join the IEA. Those who join form a coalition $S$ composed of $s$ signatories. Those remaining outside of the coalition $(n-s)$ are the non-signatories or singletons. In the second stage of the game, signatories coordinate their actions to maximize their collective net benefits. Conversely, non-signatories maximize their individual payoffs. A common payoff specification for country $i$ where $b$ and $c$ are the benefit and cost parameters, respectively, is that of Barrett's (1994) emission abatement model:

$$
\pi_{i}=b Q-\frac{c}{2} q_{i}^{2} \quad \forall i \notin S,
$$

with $b>0$ and $c<0$. In Barrett's model, $Q$ represents global abatement and $q_{i}$ is country $i$ 's abatement level. Notice that abatement is usually assumed to be additive, i.e., $Q=\sum q_{i}$. We modify the interpretation of $q_{i}$ in our model, and we assume that it represents the conservation level in country $i$.

The first feature we include in our model of an IEA for biodiversity conservation is the specification of a hyperbolic cost function. This specification is crucial for the biodiversity case because countries have a given biodiversity endowment that can be preserved within their borders.

As mentioned in the introduction we use a species count as an approximate measure of biodiversity since usually more detailed information capturing (taxonomic or other) distances between species is not available. Using a species count, we define in our model the biodiversity endowment of a country as the number of species initially present, denoted by $\bar{q}$. This endowment determines an upper bound of conservation that is assumed to be equal for all countries (but we relax this assumption later on). We also define the conservation level of any country $i \in N$, denoted by $q_{i}$, as the number of species preserved within the country. We use hyperbolic cost functions (instead of quadratic cost functions) reflecting that marginal costs of conservation increase monotonously and without limits as a country approaches its maximum level of conservation possible, $\bar{q}$.

The second feature of our model is the inclusion of local benefits of biodiversity conservation in addition to the global benefits of conservation. Together with the benefits of global conservation (which is a public good), countries obtain local, secondary benefits from their local biodiversity conservation. Benefits of local conservation can vary from one country to another. Improvements of recreational opportunities, better air quality, decrease in ambient temperature, and health improvements are some of the secondary benefits that can be perceived on a local scale as a result of conservation activities (Elmqvist 2012).

Finus and Rübbelke (2013) incorporate local (ancillary) benefits in the standard twostage, cartel formation game of climate change. In one of their examples, they consider a payoff function with linear local and global benefits and quadratic costs. To study the inclusion of local benefits of biodiversity conservation in our model, we use Finus and Rübbelke's (2013) model as a benchmark, but we use hyperbolic cost functions instead of the commonly used quadratic cost functions as explained before. The payoff function for country $i$ is: 


$$
\pi_{i}=b Q+\alpha b q_{i}-c\left(\frac{q_{i}}{\bar{q}-q_{i}}\right) \quad \forall i \notin S
$$

In this first model variant, $Q$ represents the sum of the number of species preserved in all countries $Q=\sum q_{i}, q_{i}$ is the conservation level in country $i$ (number of species preserved within country $i$ ), and $\bar{q}$ is any country's maximum level of conservation possible, where $\bar{q}>0$. Also, $b$ and $c$ are the benefit and cost parameters, respectively, $b>0, c>0$, and $\alpha$ is the parameter that measures the weight of benefits from local conservation, $\alpha \geq 0$. Notice that in our model specification any conservation level is associated with a positive cost, i.e., no conservation is for free. For this model, the equilibrium conservation levels in the second stage of the game are:

$$
\begin{aligned}
& q_{i}^{*}(s)=\left(\bar{q}-\delta \frac{1}{\sqrt{s+\alpha}}\right) \quad i \in S, \\
& q_{i}^{*}(s)=\left(\bar{q}-\delta \frac{1}{\sqrt{1+\alpha}}\right) \quad i \notin S,
\end{aligned}
$$

with $\delta \equiv \sqrt{\frac{c \bar{q}}{b}}$. Both signatories and singletons have dominant strategies for their conservation levels. Their optimal conservation levels depend on the benefit and cost parameters, on the upper bound of conservation and on the parameter $\alpha$ of local benefits of conservation. Conservation efforts of other countries have no effect on the optimal conservation efforts of country $i$. Hence, under this model specification, higher conservation efforts in one country do not crowd out conservation efforts in other countries.

\subsubsection{Coalition stability}

Given the conservation choices of the second stage, the payoff of a signatory in coalition $S$ is denoted by $\pi_{i}^{c}(s)$ and the payoff of a singleton is denoted by $\pi_{i}^{o}(s)$. A subgame perfect equilibrium implies that given the choices at the second stage, signatories do not have an incentive to leave the coalition $S$, and singletons do not have an incentive to join the coalition $S$. We can say that coalition $S$ is internally stable (IS) and externally stable (ES) if:

$$
\begin{array}{ll}
\text { IS: } \pi_{i}^{c}(s) \geq \pi_{i}^{o}(s-1) & \forall i \in S, \\
\text { ES: } \pi_{i}^{o}(s) \geq \pi_{i}^{c}(s+1) & \forall i \notin S .
\end{array}
$$

We derive from our model the following internal and external stability conditions (see "Appendix"):

$$
\begin{array}{ll}
\text { IS: } \frac{(s-1)}{\sqrt{s-1+\alpha}} \geq 2(\sqrt{s+\alpha}-\sqrt{1+\alpha}) & \forall i \in S, \\
\text { ES: } 2(\sqrt{s+1+\alpha}-\sqrt{1+\alpha}) \geq \frac{s}{\sqrt{s+\alpha}} \quad \forall i \notin S .
\end{array}
$$

Note that both conditions are independent of $b$ and $c$. The conditions are dependent on the number of signatories and on the parameter $\alpha$ that weighs the local benefits of conservation. From conditions (6) and (7), it can be shown that the model with hyperbolic cost 
functions and local benefits of conservation leads to an equilibrium number of signatories of $s \leq 2$ for any $n \geq 2$, irrespective of the size of $\alpha$.

Finus and Rübbelke's model (2013) with linear benefit functions (and local benefits included) and quadratic cost functions leads to a maximum number of signatories in a stable coalition of $s \leq 3$ or any $n \geq 2$, also irrespective of the size of $\alpha$. They conclude that the inclusion of local benefits has no impact on the size of the stable coalition. We observe in our model smaller stable coalitions compared to a model with quadratic cost functions. This is an implication of the use of hyperbolic cost functions, and not of inclusion of local benefits.

We confirm, for our model, that including local benefits does not alter the equilibrium size of the coalition. Results are not encouraging in this case since the size of stable coalitions in our model is smaller compared to Finus and Rübbelke's (2013) findings for quadratic cost functions in the emission abatement game. We argue that a hyperbolic cost function is a more appropriate specification of the costs of biodiversity conservation to reflect the unlimited increase in marginal costs when conservation approaches a natural upper bound. Yet, results suggest that forming effective biodiversity agreements could be even more difficult than forming international agreements for pollution abatement.

\subsection{Subadditivity of the global conservation function}

The third feature we include in our model is the subadditivity of the global conservation function. Conventional models of IEAs for climate change define global abatement as the sum of the individual abatement levels of all countries, $Q=\sum q_{i}$. We argue that, for the case of biodiversity, this specification is not convincing.

There is no official, standardized measurement for biodiversity conservation. Some of the common measurements to account for conservation are: size of protected areas, number of species, and number of ecosystem services. The measurement of biodiversity conservation by means of the size of protected areas presumes that each protected hectare offers the same level of biodiversity. This presumption seems to be too strong if we compare, e.g., one hectare of protected rainforest in Indonesia with one hectare of protected dryland in Kenya.

As mentioned before, in this paper we make use of a species count as a pragmatic approach to measure biodiversity (see Weikard 2002). We define global biodiversity conservation as the total number of species preserved in the world. Note that with this definition global conservation is not simply the sum of individual countries' conservation. We need to account for the fact that some species are jointly preserved in two or more countries (Weitzman 1998). If, say, species $z$ is preserved in country $i$ and in country $j$, then species $z$ should be counted only once in a measure of global biodiversity. Hence, our suggestion is to use a subadditive global conservation function.

Our concept of conservation is based on the definition from the glossary of IUCN (2016), which states that conservation is "the protection, care, management and maintenance of ecosystems, habitats, wildlife species and populations, within or outside of their natural environments, in order to safeguard the natural conditions for their long-term permanence." Since our measure of biodiversity derives from a species count, the definition of conservation applied in our model focuses on the preservation, care, management and maintenance of species specifically. ${ }^{1} \mathrm{We}$ recognize that there are limitations associated to the use of our species count methodology. Although recent studies estimate that there are around 8.7 million species in the world (Mora et al. 2011), only 1.2 million have been

"We use the terms "conservation" and "preservation" as synonyms throughout the manuscript. 
named and described, and it is suggested that there are many more species of which we are not (yet) aware. In short, the total number of species on Earth is unknown. Furthermore, values of species can vary with respect to their characteristics, for example, if they have direct use values (e.g., food crops, medicinal plants) or a specific role in an ecosystem (e.g., keystone species). In spite of these arguments, and for the purpose of our analysis and simulations, we assume (1) that there is a fixed number of species to represent the maximum number of species that can be preserved per country, and (2) that all species have the same value. The latter assumption is not essential but eases our analysis. We leave refinements of these assumptions for further research, but offer a brief discussion in the Extensions section below.

The conservation level $q_{i}$ represents the total number of species that are preserved in country $i$. Global biodiversity conservation $G$ describes how the aggregate conservation maps into species protection. $G$ must be smaller or equal to the sum of the individual conservation levels, $G \leq Q=\sum q_{i}$. In line with this, global biodiversity conservation $G$ is a subadditive function of the sum of conservation levels of all countries, $Q=\sum q_{i}$. Generally, a function $f: A \rightarrow \boldsymbol{R}$ is subadditive if

$$
f(x+y) \leq f(x)+f(y) \quad \forall x, y \in A .
$$

We specify global conservation $G$ in our model as a parabolic function of $Q$ to represent subadditivity. However, other functional forms would also allow the inclusion of subadditivity in the model (e.g., a natural logarithmic function). The specification of global biodiversity conservation is:

$$
G=\theta\left(-Q^{2}+2 \bar{Q} Q\right),
$$

where $\theta$ is a parameter for subadditivity and $Q$ is the sum of the species preserved in all countries. We define $\bar{Q}$ as the sum of individual countries' species endowments $\bar{q}$. That is, for $n$ symmetric countries, $\bar{Q}=n * \bar{q}$. The maximum value that $G$ can take, $\bar{G}$, is obtained when $Q=\bar{Q}$ (see Fig. 1).

Subadditivity requires concavity of $G$ but concavity is not sufficient for subadditivity. Additionally, we require $\frac{1}{n \bar{Q}} \leq \theta \leq \frac{1}{2 \bar{Q}}$ to ensure that the slope of the function is always less than 1 in its relevant part, $0 \leq Q \leq \bar{Q}$, and that the global species endowment must (weakly) exceed the species endowment in any individual country. ${ }^{2}$

We can now proceed to put together all three abovementioned features of an IEA for biodiversity conservation: hyperbolic cost functions, local benefits of conservation and subadditivity of the global conservation function $G$. We use the payoff function from Eq. (1) and we include Eq. (8) in the benefit function to analyze the impact of a subadditive function for global biodiversity conservation. The payoff function for country $i$ with the subadditivity feature is:

$$
\pi_{i}=b\left[\left(\frac{\bar{G}}{\bar{Q}^{2}}\right)\left(-Q^{2}+2 \bar{Q} Q\right)+\alpha q_{i}\right]-c\left(\frac{q_{i}}{\bar{q}-q_{i}}\right) \quad \forall i \notin S,
$$

where we substitute $\theta$ in Eq. (8) by $\frac{\bar{G}}{\bar{Q}^{2}}$.

\footnotetext{
${ }^{2}$ Barrett (1994) also considers a quadratic specification for the benefit function. However, the quadratic function stated in his model is subadditive only for certain parameters but not in general. In our model, we make sure that we include parameter constraints such that our quadratic function is always subadditive, i.e., $f^{\prime}\left(q_{i}\right)<1$.
} 


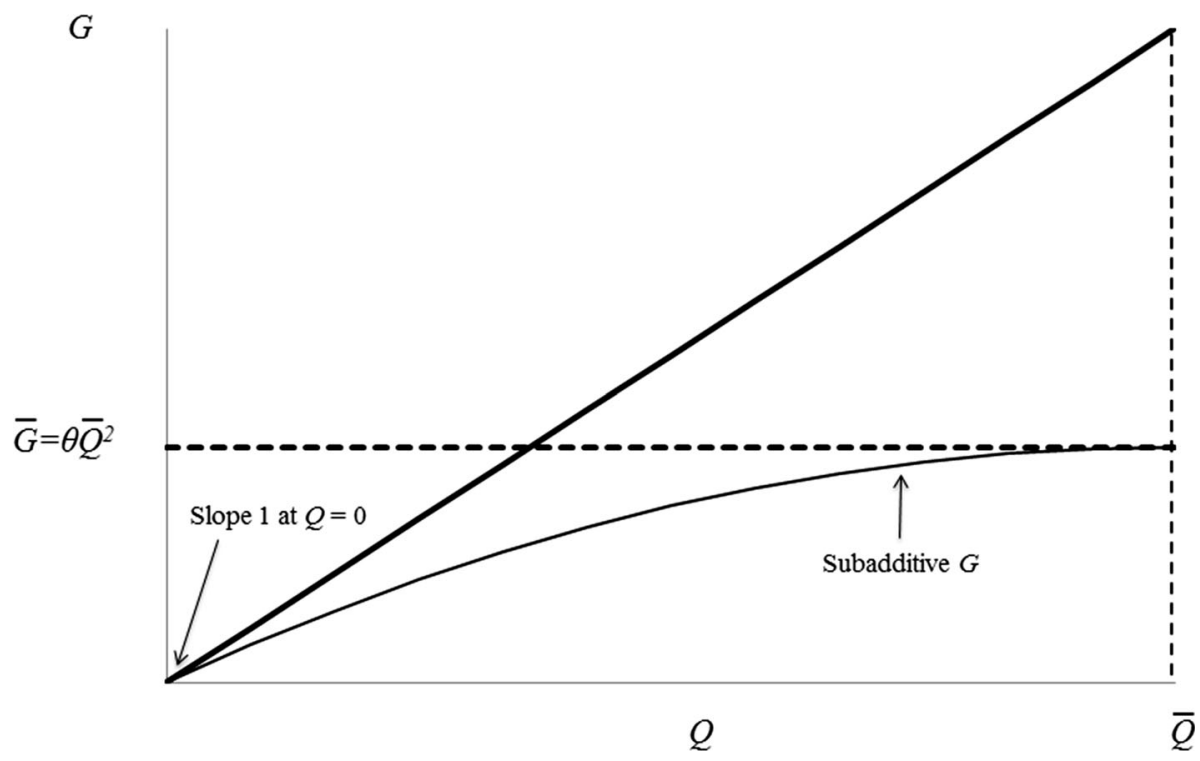

Fig. 1 Subadditivity of the global biodiversity conservation function $G$

A full characterization of the reaction functions of this model and of its analytical solution when solved by computer software does not yield a useful interpretation as we obtain extensive polynomials for $q_{i}^{*}(s)$. To obtain further insights, we perform a numerical simulation. We first determine arbitrary values for the parameters of the base model and change the value of each of these parameters separately to study the impact of these changes on the size of stable coalitions.

We set the number of countries to $n=12$ for all our model variants to facilitate our numerical appraisal. Since we consider symmetric countries, we maintain our assumption of $\bar{Q}=n * \bar{q}$. The parameter values set for the base case of the model with subadditivity in the global conservation function, local benefits and hyperbolic cost functions are: $b=1$, $c=1000, \alpha=1, \bar{q}=1625$ and $\bar{G}=6500$.

Numerical simulations reveal that for the base model the maximum size of a stable coalition is $s^{*}=2$. There are 66 stable coalitions in total, which means that all possible coalitions composed of any 2 countries are stable.

In order to evaluate the success of coalition formation in welfare terms, we make use of the relative welfare measure suggested by Eyckmans and Finus (2006) known as the "closing the gap index" (CGI). The welfare CGI is defined as:

$$
\mathrm{CGI}^{V}=\frac{V^{E}-V^{\mathrm{NC}}}{V^{\mathrm{FC}}-V^{\mathrm{NC}}}
$$

where $V^{E}$ is the global payoff of the best coalition in equilibrium, $V^{\mathrm{NC}}$ is the global payoff when there is no cooperation, $V^{\mathrm{FC}}$ is the global payoff in the social optimum (full cooperation). Notice that the index satisfies $0 \leq \mathrm{CGI}^{V} \leq 1$.

For the base model with a stable coalition of 2 members, the value of the index is $\mathrm{CGI}^{V}=0.072$. This means that $7.2 \%$ of the potential gains from full cooperation can be reaped through the formation of a stable agreement with 2 members. We also calculate a 
CGI to express relative gain in terms of global conservation. The definition of the global biodiversity CGI is analogous to $\mathrm{CGI}^{V}$ :

$$
\mathrm{CGI}^{G}=\frac{G^{E}-G^{\mathrm{NC}}}{G^{\mathrm{FC}}-G^{\mathrm{NC}}}
$$

For the base model with a stable coalition of 2 members, the value of the index is $\mathrm{CGI}^{G}=0.054$. An agreement with a stable coalition of 2 members preserves $5.4 \%$ of the global biodiversity that the grand coalition would preserve in addition to those preserved in the absence of an agreement.

In the remainder of this section, we examine the impact of our model parameters on the size of the stable coalition. For the model with linear global and local benefits, and hyperbolic cost functions (Sect. 2.1) results are robust for any parameter change: the size of the largest stable coalition is always $s^{*}=2$. For the model with subadditivity, most changes in parameter values also result in a stable coalition of a maximum of 2 members, including that in which $\alpha<1$. However, a larger stable coalition of size 3 is obtained when local benefits of conservation are larger than in the base model (increase of $\alpha=1$ to $\alpha=100$ ). If the local benefit parameter increases to $\alpha=1000$, full cooperation is achieved $\left(s^{*}=12\right)$. This would represent a set of countries with characteristics such as Australia, Costa Rica, Ecuador or Madagascar where conservation yields considerably local high benefits. Yet, this latter case is an instance of Barrett's (1994) "paradox of cooperation": the gap between the aggregate payoff in the stable grand coalition and the all singletons coalition structure is very small, and thus the need for cooperation is limited.

Our numerical analysis shows that the inclusion of subadditivity in the global biodiversity conservation function $G$ allows for equilibrium coalitions larger than 2 . In the same way that Barrett's (1994) quadratic-quadratic model shows larger coalitions to be stable, our three-feature model allows for coalitions larger than 2.

Table 1 summarizes the payoff functions of the different models we have studied under the assumption of symmetric countries. We include, as a point of reference, other standard models from the IEA literature to compare functional forms and the maximum size of a stable coalition. In the next section, we focus on coalition stability when we relax the assumption of symmetric countries.

\section{IEA stability for biodiversity conservation with asymmetric countries}

In this section, we examine stability in our three-feature model of an IEA for biodiversity conservation when countries are asymmetric. We consider two types of asymmetries separately. First, we deal with asymmetry of countries' benefits and costs of conservation, defined as "double-sided asymmetry." Then, we examine countries with different upper bounds of conservation. For both types of asymmetries, we analyze coalition stability without and with the inclusion of a transfer scheme.

\subsection{Three-feature model with double-sided asymmetry}

We start by assuming that countries have different benefits and costs of conservation. We introduce the scenario of double-sided asymmetry where each country belongs to one of four different categories: 
Table 1 Equilibrium number of signatories for various payoff functions, as compared to some examples from main IEA literature ${ }^{\mathrm{a}}$

\begin{tabular}{|c|c|c|c|c|}
\hline \multirow[t]{3}{*}{ Model } & \multicolumn{3}{|l|}{ Payoff function } & \multirow{3}{*}{$\begin{array}{l}\text { Largest } \\
\text { stable coalition } \\
\left(s^{*}\right)\end{array}$} \\
\hline & \multicolumn{2}{|l|}{$\begin{array}{l}\text { Benefits of biodiversity } \\
\text { conservation }\end{array}$} & \multirow{2}{*}{$\begin{array}{l}\text { Costs of } \\
\text { biodiversity } \\
\text { conservation }\end{array}$} & \\
\hline & Global benefits & $\begin{array}{l}\text { Local } \\
\text { benefits }\end{array}$ & & \\
\hline $\begin{array}{l}\text { 1. Barrett's (1994) model: linear } \\
\text { benefit and quadratic cost functions }\end{array}$ & $b Q$ & & $c q_{i}^{2}$ & 3 \\
\hline $\begin{array}{l}\text { 2. Finus and Rübbelke's (2013) model: } \\
\text { linear benefit and quadratic cost } \\
\text { functions with the inclusion of } \\
\text { ancillary (local) benefits }\end{array}$ & $b Q$ & $\alpha b q_{i}$ & $c q_{i}^{2}$ & 3 \\
\hline $\begin{array}{l}\text { 3. Linear benefit and hyperbolic cost } \\
\text { functions with the inclusion of local } \\
\text { benefits }\end{array}$ & $b Q$ & $\alpha b q_{i}$ & $c\left(\frac{q_{i}}{\bar{q}-q_{i}}\right)$ & 2 \\
\hline $\begin{array}{l}\text { 4. Barrett's (1994) model: quadratic- } \\
\text { quadratic functions }\end{array}$ & $b\left(Q-\frac{Q^{2}}{2}\right) / N$ & & $\frac{c q_{i}^{2}}{2}$ & $s^{*} \in[2, N]$ \\
\hline $\begin{array}{l}\text { 5. Three-feature model. Subadditivity } \\
\text { of the global conservation function } \\
G \text {, local benefits of biodiversity } \\
\text { conservation and hyperbolic cost } \\
\text { functions. }\end{array}$ & $b\left(\frac{\bar{G}}{\bar{Q}^{2}}\right)\left(-Q^{2}+2 \bar{Q} Q\right)$ & $\alpha b q_{i}$ & $c\left(\frac{q_{i}}{\bar{q}-q_{i}}\right)$ & $s^{*} \in[2, N]$ \\
\hline
\end{tabular}

${ }^{a}$ Models 1, 2 and 4 are existing models in the IEA literature that we include for comparison. Models 3 and 5 are the actual models derived from this article

1. Countries with high benefits of biodiversity conservation and high costs of biodiversity conservation (shorthand BC),

2. Countries with high benefits of biodiversity conservation and low costs of biodiversity conservation (shorthand $\mathrm{Bc}$ ),

3. Countries with low benefits of biodiversity conservation and high costs of biodiversity conservation (shorthand bC),

4. Countries with low benefits of biodiversity conservation and low costs of biodiversity conservation (shorthand bc).

An example of a BC country is Indonesia. According to the GEF benefits index for biodiversity (World Bank 2008), the relative biodiversity potential of Indonesia is very high; however, conservation activities are relatively costly for the government. Indonesia is one of the richest countries in terms of biodiversity. Yet, opportunity costs of conservation are very high as industry is expanding rapidly in this country, putting pressure on its nature. The Bc category reflects countries like Australia. This country also has relatively high benefits of preserving biodiversity. Yet, opportunity costs of conservation are relatively lower in Australia. An example of a bC country is Mali, where the biodiversity potential in terms of represented species and diversity of habitats is low but the costs of conservation activities are high. Finally, the bc category reflects countries like Finland where both biodiversity values and costs of biodiversity conservation are relatively low.

Our model shares some features with a model developed by Winands et al. (2013) but differs in some important aspects. Firstly, the specification of the model is different. While 
Winands et al. (2013) use a constant elasticity of substitution (CES) benefit function to consider varying degrees of substitutability between ecosystems, we use a quadratic benefits function to represent the subadditive aspect of global biodiversity conservation. Secondly, Winands et al. (2013) use protected hectares as their measure of conservation while we suggest a species count. Thirdly, the four categories of countries from our model differ from those presented in their study. In Winands et al. (2013) countries differ in two dimensions: wealth and biodiversity richness, whereas in our model countries differ in benefits and costs of conservation. Finally, we consider a model with $n=12$ countries (with 3 countries in each category) which allows to account for many different kind of agreements, i.e., coalitions consisting of different numbers and types of countries. Winands et al. (2013) confine their analysis to four countries, $n=4$, one of each type.

We consider the payoff function of Eq. (9) in Sect. 2.2. We maintain the parameter values of the base case, i.e., $\alpha=1, \bar{q}=1625$ and $\bar{G}=6500$, with the exceptions of the benefit and cost parameters that vary now depending on the country type; see Table 2.

Numerical simulations reveal that the maximum size of a stable coalition for the model with double-sided asymmetry is equal to the model with symmetry: $s^{*}=2$. The difference is that for the asymmetric case there are only 3 stable coalitions, and these are composed of any 2 countries with a comparative advantage of conservation: high benefits and low costs of conservation (Bc type). A possible example would be an agreement for conservation between Australia and New Zealand. For the base model under asymmetry with a stable coalition of 2 members, the $\mathrm{CGI}^{V}$ is 0.004 . The formation of a coalition with 2 members achieves $0.4 \%$ of the potential gains from full cooperation. In terms of conservation outcomes for the stable coalition, we find that $\mathrm{CGI}^{G}=0.005$. Gains in payoff and global conservation are small.

We then examine the impact of the other model parameters on the size of the stable coalition. We performed a sensitivity analysis where we modified, one by one, the value of the parameters $\alpha, \bar{q}$ and $\bar{G}$. Figure 2 shows the maximum size of an equilibrium coalition in the three-feature model under double-sided asymmetry for different parameter values.

According to the sensitivity analysis, results are robust to the changes in the parameter values of $\bar{q}$ and $\bar{G}$ : the maximum size of the stable coalition of the three-feature model under double-sided asymmetry is $s^{*}=2$. For changes in the parameter values of local benefits of conservation, the results are different. A larger stable coalition of size 6 (consisting of all 3 members of the BC type and all 3 of the Bc type) is achieved when local benefits of conservation increase from $\alpha=1$ to $\alpha=100$. We conclude that, in the absence of transfers, the size of a stable coalition under double-sided asymmetry is either maintained $\left(s^{*}=2\right.$ ) or increased (from $s^{*}=3$ to $s^{*}=6$ ) when compared to the model with symmetry. This result differs from findings of Winands et al. (2013) where asymmetry in

Table 2 Value of the benefit and cost parameters for the different country types

\begin{tabular}{llcc}
\hline Country category & Countries of this type in the model & \multicolumn{2}{c}{ Parameter values } \\
\cline { 2 - 4 } & & $b$ & $c$ \\
\hline BC & $\mathrm{C} 1, \mathrm{C} 2, \mathrm{C} 3$ & 100 & 10.000 \\
$\mathrm{Bc}$ & $\mathrm{C} 4, \mathrm{C} 5, \mathrm{C} 6$ & 100 & 1000 \\
bC & $\mathrm{C} 7, \mathrm{C} 8, \mathrm{C} 9$ & 1 & 10.000 \\
bc & $\mathrm{C} 10, \mathrm{C} 11, \mathrm{C} 12$ & 1 & 1000 \\
\hline
\end{tabular}



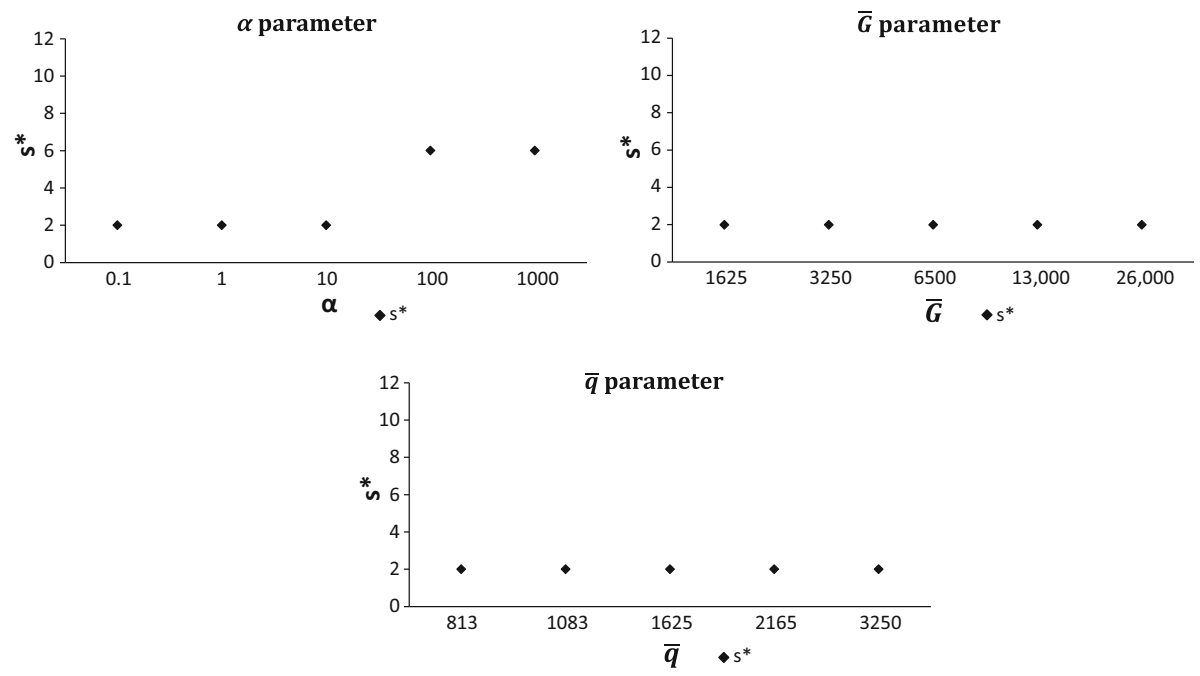

Fig. 2 Size of stable coalitions for given changes in parameter values of the model with double-sided asymmetry. Only the value on the horizontal axis is modified. All other values remain constant as in the base case of the model

ecosystems and wealth reduces the size of a stable coalition compared to the symmetric case.

With the exception of the case where local benefits of conservation are very high, our results are rather dismal in terms of the creation of a large self-enforcing IEA. In terms of policy implications, the stability of small stable coalitions of 2 members may suggest that the development of bilateral agreements could be more desirable for effective conservation than one single large agreement. An analysis of coalition stability with multiple coalitions is beyond the scope of our study; yet, it can be explored in future research.

From the analysis we observe that cooperation between countries in a two-sided asymmetry game is robust with respect to changes in (1) the maximum level of global biodiversity conservation $(\bar{G})$ and (2) the species endowment in each country $(\bar{q})$, but is positively related to increases in local benefits of conservation $(\alpha)$. Even though higher local benefits of conservation translate into larger coalitions, they do not necessarily translate into more efficient IEAs. The reason is that the additional incentives to preserve are due to high local benefits, irrespective of a country's participation in an IEA. Therefore, for this case, the gains in cooperation in a large stable IEA are relatively low compared to cases where local benefits are small.

\subsubsection{Inclusion of transfers in the model with double-sided asymmetry}

Transfers allow signatory countries of an agreement to "buy international cooperation" (Fuentes-Albero and Rubio 2010). They can be used to set incentives to join the coalition, so that larger coalitions may satisfy the internal stability condition (Pavlova and de Zeeuw 2013). We apply an optimal sharing rule that guarantees that a coalition is internally stable when the coalition payoff (weakly) exceeds the sum of the outside option payoffs (Weikard 2009). We implement this sharing rule because it emphasizes the importance of individual outside options. In the context of international agreements where membership is 
voluntary, it is natural to assume that each member should not be worse off than in a situation where it leaves the coalition while others maintain their membership. We also assume that a country would join the coalition if it were indifferent between joining and staying out.

In general transfers increase the chances for larger stable biodiversity agreements (see also Winands et al. 2013). One way to implement these transfers would be by means of an international market for biodiversity credits, as has been suggested by Alvarado-Quesada et al. (2014).

Table 3 compares the results obtained in our model with double-sided asymmetry without transfers with the results when an optimal transfer rule is applied.

From the results reported in Table 3, we find that the number of stable coalitions increases for all cases when transfers are allowed except for the case of $\alpha=100$, where the number of stable coalitions remains constant (63).

Moreover, the size of stable coalitions systematically increases for all parameter changes when transfers are included. The largest stable coalitions when transfers are not allowed are composed of 2 members of the Bc type (relatively high benefits of conservation). Only for $\alpha=100$, the largest coalition has 6 members: 3 members of the BC type and 3 of the Bc type. When transfers are allowed, however, we find stable coalitions of up to 7 members for all parameter changes.

Notice that, although there are also stable coalitions of 2 members when transfers are allowed, the best coalitions in terms of global payoff are composed of 7 members: 1 member of the BC type, 3 members of the bC type, and 3 members of the bc type. The composition of the largest stable structure varies with respect to the case without transfers: it has 1 member with relatively high benefits of conservation and 6 members with relatively low benefits of conservation. The reason why this coalition is more effective is that, despite being composed mainly of countries with relatively low benefits of conservation, global conservation is higher than in a stable coalition of 2 members with high benefits of conservation.

Notice also that, in our results with transfers, the grand coalition is not stable for any of the parameter changes. This result differs from that of Winands et al. (2013) in which, under asymmetry, the grand coalition is always stable when transfers are allowed. But clearly a grand coalition is easier to stabilize when the number of players is small.

\subsection{Three-feature model with asymmetry in the natural upper bound of conservation}

Although useful for the analysis in Sect. 2, the assumption of an equal biodiversity endowment for all countries is very specific. Therefore, in this subsection we study three examples in which countries are asymmetric with respect to their natural upper bound of conservation $\bar{q}$ and symmetric with respect to all other parameters. Even though we set different upper bounds of conservation, we maintain the assumption of the symmetric case that the sum of all countries' species endowment is $\bar{Q}=19,500$ for all three scenarios.

\section{Scenario I}

For the first scenario, we set the same value of $\bar{q}=1500$ for 11 countries, and for 1 country (C12) we double the size of the natural upper bound of conservation, $\bar{q}=3000$.

Results show that the maximum size of a stable coalition is $s^{*}=2$. All possible coalitions composed of 2 members are stable (66 coalitions in total). Eleven of these latter coalitions have the highest payoff and all of them include $\mathrm{C} 12$ as a member. $\mathrm{C} 12$ preserves 


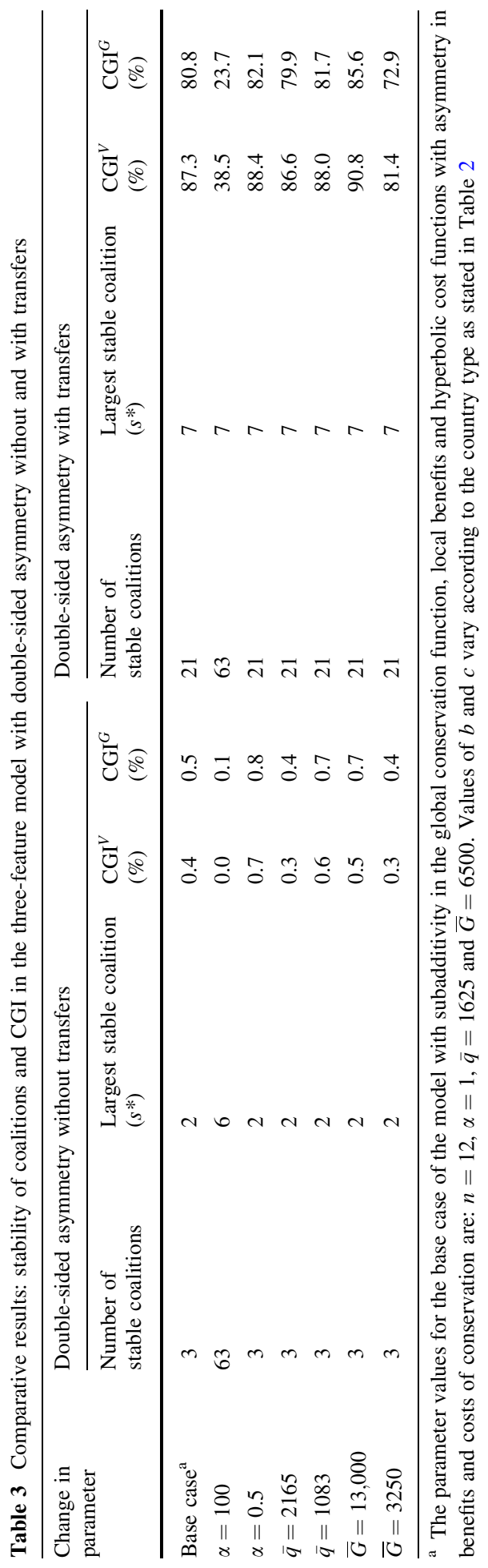


more than a half of its endowment $\bar{q}$. The other member of the coalition of 2 preserves around $40 \%$ of its endowment, whereas the singletons preserve less than a third of theirs.

\section{Scenario II}

For the second scenario, we set the same $\bar{q}=1218$ for 11 countries, and for 1 country (C12) the natural upper bound of conservation is set 5 times as large, i.e., $\bar{q}=6090$.

Results show that also for this scenario the maximum size of a stable coalition is $s^{*}=2$. However, only 55 coalitions composed of 2 members are stable, and none of them includes $\mathrm{C} 12$ as a member. Signatory countries preserve around one-third of their biodiversity endowment, $\mathrm{C} 12$ as a singleton preserves two-thirds of its endowment, and the rest of the singletons preserve less than $25 \%$ of their endowment.

\section{Scenario III}

For the third scenario, we consider 10 countries with the same value of $\bar{q}=1392$, and 2 countries (C11 and $\mathrm{C} 12)$ with two times that size of the natural upper bound of conservation, i.e., $\bar{q}=2784$.

Without transfers, the maximum size of a stable coalition for this scenario is also $s^{*}=2$. There are 65 stable coalitions in total, which are all possible coalitions of 2 members except the coalition formed by $\mathrm{C} 11$ and $\mathrm{C} 12$. Coalitions with the highest payoff are those where either $\mathrm{C} 11$ or $\mathrm{C} 12$ joins. For such cases, singletons with a lower $\bar{q}$ preserve $30 \%$ of their endowment, and the signatory with the lower $\bar{q}$ preserves around $37 \%$ of its endowment; whereas the singleton with the higher $\bar{q}$ (either $\mathrm{C} 11$ or $\mathrm{C} 12$ ) preserves almost half of its endowment while the signatory with a higher endowment preserves around $56 \%$ of its endowment. We observe that countries with a higher biodiversity endowment preserve larger shares of their $\bar{q}$ than those with a lower biodiversity endowment; this is regardless of whether they act as signatories or as singletons. We attribute this result to the hyperbolic form of the cost function: marginal costs of conservation become lower as the upper bound of conservation becomes higher.

\subsubsection{Inclusion of transfers in the model with asymmetry in the natural upper bound of conservation}

Table 4 shows a comparison between the results obtained in the three scenarios of asymmetric countries in their natural upper bound of conservation $\bar{q}$ without transfers and the model when the optimal transfer rule is applied.

We observe from Table 4 that the inclusion of transfers does not have an impact on the size of the largest stable coalition in any of the three scenarios. In particular, Scenario I does not show any variation in either the number of stable coalitions or the CGIs. In Scenario II, however, the number of stable coalitions and the CGI indexes increase. For this scenario $10.4 \%$ of the potential gains from full cooperation can be reaped when allowing for transfers, as compared to $6.5 \%$ without transfers. Also, when we allow for transfers, global conservation increases even though the size of the largest coalition remains unchanged: now $7.8 \%$ of global conservation under the grand coalition is preserved. Finally, Scenario III also shows larger CGIs, however, to a lesser extent than Scenario II.

The outcomes of the scenarios suggest that under the inclusion of transfers, Scenario II shows the largest potential gains from cooperation and conservation. Even though the maximum size of a stable coalition does not change when transfers are included, all countries are willing to individually transfer part of their gains to the country with the highest biodiversity endowment (C12) to make sure it is part of an agreement of 2 


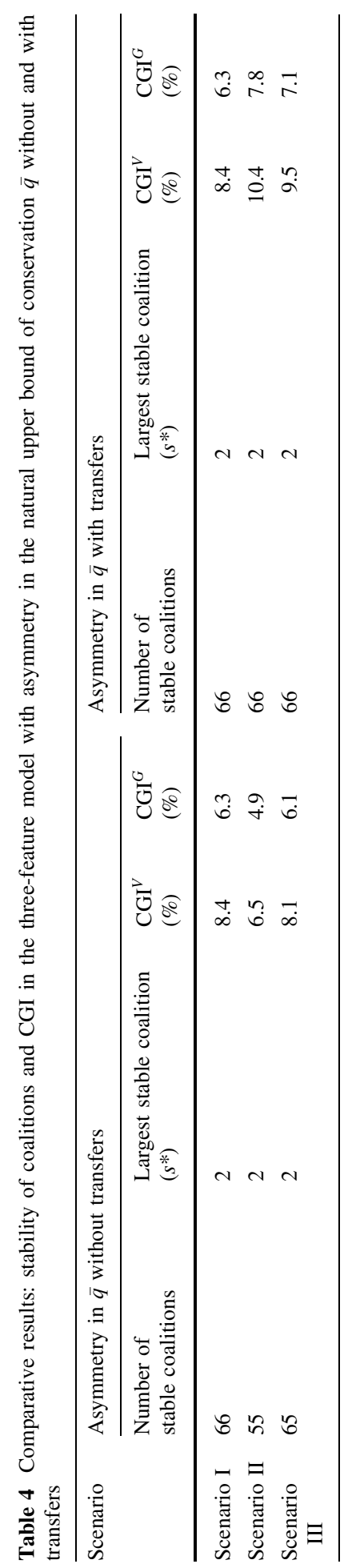


members. Coalitions of 2 members which include $\mathrm{C} 12$ have the best global payoff. Not surprisingly, we observe that trade is more effective if the countries involved are different.

\section{Extensions}

In the previous sections, we developed a non-cooperative game-theoretical model of an IEA for biodiversity conservation. In order to do so, we established a set of assumptions to simplify the appraisal of the coalition stability analysis. In this section, we describe possible extensions of the model where some of these assumptions are dropped. We address the following extensions: (1) an alternative game-theoretical approach to the analysis of coalition stability, (2) the integration of empirical results in the theoretical model, and (3) the use of alternative assumptions for our species conservation model.

\subsection{Alternative approaches to coalition stability analysis}

Non-cooperative approaches tend to result in the formation of small, stable coalitions (Finus 2008). We have developed a non-cooperative cartel formation game where only one coalition is formed. This means that a single agreement is proposed and defectors cannot join a different one (Carraro and Siniscalco 1998). This poses a limitation on the coalition structure since it does not allow for the possible establishment of multiple partial coalitions or bilateral agreements. Our findings suggest, however, that there might be scope for multiple, smaller coalitions which is in line with results of Asheim et al. (2006).

The IEA literature has analyzed models with a limited number of different types of countries where small stable coalitions can be expanded to larger stable coalitions by means of ex-post transfers. Chou and Sylla (2008) consider sequential accession to an agreement and find that a small stable coalition formed in the first stage of their game can be expanded to a larger one (or even the grand coalition) in the second stage. Asymmetry of countries makes an expansion more likely when monetary transfers are employed. In a similar way, Biancardi and Villani (2010) implement a transfer scheme in a model of pollution abatement as a way to expand a partial coalition to the grand coalition. Weikard (2011) examines the case when countries make an irrevocable commitment upon entering a coalition, such that they cannot leave after entry. In this case, sequential accession can generate a stable grand coalition after a limited number of rounds of accession.

A further extension of the model would be to consider a cooperative game-theoretical approach. Cooperative game theory focuses on the grand coalition of all countries and that coalition can share the gains from cooperation such that no sub-coalition has an incentive to break away from global cooperation (Carraro and Siniscalco 1998). Chander and Tulkens $(1995,1997)$ have shown that for the global commons the core of the game is nonempty and that, given the $\gamma$-core assumption (i.e., upon any deviation of a subset of countries, other countries act as singletons), the grand coalition is an equilibrium coalition structure (Tulkens 1998; Chander 2007). This suggests that a cooperative approach would allow for grand stable coalitions to be achieved under less strict circumstances.

\subsection{Integration of empirical information into the theoretical model}

Our model presents analytical results and sensitivity analyses-by means of a simulation exercise - of different parameters to study the maximum size of stable coalitions and the 
gains of cooperation derived from such coalitions. Our modeling choices were driven by the need for a more general understanding of the drivers of coalition stability and how particular features of the biodiversity case impact the scope for getting effective agreements. A further desirable contribution to the model would be the improvement of its empirical relevance by integrating real-world data into the theoretical model framework, as others have previously done (Winands et al. 2013). Parameterization of the model to conduct a numerical exercise with empirical data would shed further light on policy implications of coalition formation in the biodiversity context.

\subsection{Alternative assumptions for our species conservation model}

In our analysis, we adopt the assumption that all species have the same value to facilitate the appraisal of the model. Yet, we recognize that this assumption poses a simplification and therefore limits the policy relevance of results. This assumption has been debated. For instance, Brown and Shogren (1998) contested the underlying arguments of the reauthorization of the Endangered Species act of 1973 because it intended to save all species without making any distinction among them when accounting for relative benefits and costs of conservation.

An alternative for future research would be to drop the assumption of equal values for all species categories. One could consider different species categories, e.g., keynote species, endangered species and abundant species, and weigh the relevance of each species in the benefits of conservation of each country. In this way, the contribution of different kinds of species to the conservation benefits will become explicit.

Another assumption would be to consider a business as usual scenario (BAU) where a certain number of species are preserved in each country without any cost, i.e., where a given set of species per country is conserved for free. Finally, one could explicitly define the composition of each country's set of species in order to observe which species are shared with other countries and which species are endemic. This could shed some light on the structure of gains from cooperation: whether countries have incentives to cooperate with others that host a similar set of species or whether they rather cooperate with countries preserving different species than the ones they preserve. Alvarado-Quesada and Weikard (2017) study such problems in spatial settings.

Finally, the notion of biodiversity conservation used in our model does not address sharing of benefits arising from genetic resources (and their ownership) as addressed by Chasek et al. (2013). In their study, coalition formation reflects conflicting interests between "the North" and "the South" in terms of ownership and use of biological resources. In the context of our model approach, ownership of biological resources can be modeled as a contest game instead of implementing the theoretical approach presented in this paper.

\section{Conclusions}

In this paper, we develop a model of IEA stability for biodiversity conservation that includes three characteristics that we consider key for the understanding of biodiversity agreements. We examine the stability of IEAs under the assumption of both symmetric and asymmetric countries, and without and with the inclusion of transfers. We derive important results that we summarize and discuss in this section. 
In the first model variant under the assumption of symmetric countries, we include (1) a hyperbolic cost function to represent the existence of a natural upper bound of conservation in each country, and (2) local benefits of conservation to describe benefits of biodiversity conservation at different scales. For symmetric countries, we obtain stable coalitions of no more than 2 signatories. These coalitions are smaller than the ones obtained in models of climate agreements that use quadratic cost functions. Furthermore, our result supports existing literature that finds that the inclusion of local benefits has no impact on the size of a stable coalition if the conservation function is additive and benefits are linear in conservation.

In the base case of our model with hyperbolic costs, local benefits and a subadditive conservation function, we also find a stable coalition of at most 2 members. Larger stable coalitions can only be achieved if local benefits of conservation are large relative to global benefits. Even full cooperation is possible, but in such a case the gains from cooperation are small.

When we include double-sided asymmetry in the three-feature model, the largest stable coalition for the parameter range considered (with the exception of changing $\alpha$ ) remains equal to the symmetric model: $s^{*}=2$. The difference lies in the composition of the stable coalitions. Stable coalitions are composed of countries with high benefits and low costs of conservation (Bc type). We also observe that, just as in the symmetric case, cooperation between countries is positively related to increases in $\alpha$. In general, the stability of small and the instability of large coalitions may suggest that several partial agreements - composed of countries of the same type-may be more effective in terms of conservation outcomes than one single international agreement.

The inclusion of transfers in the model with double-sided asymmetry systematically increases the size of stable coalitions. Transfers facilitate that "gains from trade" can be reaped. Countries with low conservation costs receive compensation for their increased conservation efforts and are, thus, incentivized to become signatories.

For the three scenarios with different natural upper bounds of conservation, we find that, in the absence of transfers, the maximum size of a stable coalition is $s^{*}=2$. Regardless of their membership status (signatories or singletons), countries with a higher upper bound of maximum biodiversity preserve a larger share of their endowment than others because conservation becomes relatively cheaper. The inclusion of transfers does not have an impact on cooperation. Still, a transfer mechanism, such as a biodiversity market where conservation credits can be traded among coalition members, would allow countries with lower biodiversity endowments to transfer part of their gains from conservation to countries with higher biodiversity endowments to make sure they become part of the agreement.

We observe that the size of the stable coalitions in our model is small as compared to real life examples of IEAs that are composed of many countries, e.g., CBD. The reason is that agreements composed of a large number of signatories are usually associated with low commitment and compliance. As noticed by Barrett and Stavins (2003) in the context of the Kyoto protocol, moderate commitments facilitate widespread participation. This results in agreements with a large number of participants but with low effectiveness.

Transfers between the members of an IEA for biodiversity redistribute the gains from cooperation and allow for more effective coalitions in terms of global conservation. A global biodiversity market could be an effective mechanism not only to increase global conservation, but also to pinpoint where conservation is more effective and what characteristics potential members of an international biodiversity agreement should have. Finally, policy-makers can build contract designs deliberately on asymmetries, i.e., the specific features of different countries, in particular when a transfer mechanism is 
implemented. Extensions of our model in future studies should address (1) coalition stability analysis in a multiple coalitions framework, (2) the inclusion of empirical results in the analysis, i.e., the construction of a calibrated model and (3) alternative assumptions for our species conservation approach.

Open Access This article is distributed under the terms of the Creative Commons Attribution 4.0 International License (http://creativecommons.org/licenses/by/4.0/), which permits unrestricted use, distribution, and reproduction in any medium, provided you give appropriate credit to the original author(s) and the source, provide a link to the Creative Commons license, and indicate if changes were made.

\section{Appendix: Proof of coalition stability conditions for the model of linear global and local benefits and hyperbolic cost functions}

If coalition member $j$ leaves coalition $S$ in the first stage, the adjusted conservation levels in the second stage become:

$$
\begin{gathered}
q_{i}^{*}(s-1)=\left(\bar{q}-\delta \frac{1}{\sqrt{(s-1+\alpha)}}\right) \quad i \in S_{-j}, \\
q_{i}^{*}(s-1)=\left(\bar{q}-\delta \frac{1}{\sqrt{1+\alpha}}\right) \quad i \notin S, i=j,
\end{gathered}
$$

with $\delta \equiv \sqrt{\frac{c \bar{q}}{b}}$.

The payoff of country $j$ in the second stage as a member of coalition $S\left(\pi_{i}^{c}(s)\right)$ and as a singleton $\left(\pi_{i}^{o}(s-1)\right)$, are the following:

$$
\begin{aligned}
\pi_{i}^{c}(s)=b\left[(n-s)\left(\bar{q}-\delta \frac{1}{\sqrt{1+\alpha}}\right)+s\left(\bar{q}-\delta \frac{1}{\sqrt{s+\alpha}}\right)\right]-\frac{c\left(\bar{q}-\delta \frac{1}{\sqrt{1+\alpha}}\right)}{\delta \frac{1}{\sqrt{s+\alpha}}} \\
\pi_{i}^{o}(s-1)=b\left[(n-s-1)\left(\bar{q}-\delta \frac{1}{\sqrt{1+\alpha}}\right)+(s-1)\left(\bar{q}-\delta \frac{1}{\sqrt{(s-1+\alpha)}}\right)\right] \\
-\frac{c\left(\bar{q}-\delta \frac{1}{\sqrt{1+\alpha}}\right)}{\delta \frac{1}{\sqrt{1+\alpha}}}
\end{aligned}
$$

The internal stability condition requires that for all $i$ in $S$

$$
\pi_{i}^{c}(s)-\pi_{i}^{o}(s-1) \geq 0
$$

or

$$
\text { IS: } \frac{(s-1)}{\sqrt{s-1+\alpha}} \geq 2(\sqrt{s+\alpha}-\sqrt{1+\alpha}) \quad \forall i \in S
$$

Now, if we assume that the singleton $j$ joins the coalition $S$ in the first stage, the firstorder conditions in the second stage become: 


$$
\begin{gathered}
q_{i}^{*}(s+1)=\left(\bar{q}-\delta \frac{1}{\sqrt{(s+1+\alpha)}}\right) \quad i \in S, i=j, \\
q_{i}^{*}(s+1)=\left(\bar{q}-\delta \frac{1}{\sqrt{1+\alpha}}\right) \quad i \notin S, i \neq j .
\end{gathered}
$$

The payoffs of country $j$ in the second stage as an outsider $\left(\pi_{i}^{o}(s)\right)$ and as a member of the extended coalition $\left(\pi_{i}^{c}(s+1)\right)$, are, respectively:

$$
\begin{aligned}
\pi_{i}^{o}(s)=b\left[(n-s)\left(\bar{q}-\delta \frac{1}{\sqrt{1+\alpha}}\right)+s\left(\bar{q}-\delta \frac{1}{\sqrt{s+\alpha}}\right)\right]-\frac{c\left(\bar{q}-\delta \frac{1}{\sqrt{1+\alpha}}\right)}{\delta \frac{1}{\sqrt{1+\alpha}}} \\
\pi_{i}^{c}(s+1)=b\left[(n-s+1)\left(\bar{q}-\delta \frac{1}{\sqrt{1+\alpha}}\right)+(s+1)\left(\bar{q}-\delta \frac{1}{\sqrt{(s+1+\alpha)}}\right)\right] \\
-\frac{c\left(\bar{q}-\delta \frac{1}{\sqrt{(s+1+\alpha)}}\right)}{\delta \frac{1}{\sqrt{(s+1+\alpha)}}}
\end{aligned}
$$

The external stability condition requires that for all $i$ not in $S$

$$
\pi_{i}^{c}(s+1)-\pi_{i}^{o}(s) \leq 0
$$

or

$$
\mathrm{ES}: 2(\sqrt{s+1+\alpha}-\sqrt{1+\alpha}) \geq \frac{s}{\sqrt{s+\alpha}} \quad \forall i \notin S
$$

\section{References}

Alvarado-Quesada, I., Hein, L., \& Weikard, H.-P. (2014). Market-based mechanisms for biodiversity conservation: a review of existing schemes and an outline for a global mechanism. Biodiversity and Conservation, 23(1), 1-21. doi:10.1007/s10531-013-0598-x.

Alvarado-Quesada, I., \& Weikard, H.-P. (2017). International cooperation on biodiversity conservation when spatial structures matter. Spatial Economic Analysis, 12(1), 27-49.

Asheim, G. B., Bretteville Froyn, C., Hovi, J., \& Menz, F. C. (2006). Regional versus global cooperation for climate control. Journal of Environmental Economics and Management, 51(1), 93-109.

Barrett, S. (1994). Self-enforcing International Environmental Agreements. Oxford Economic Papers, 46, 878-894.

Barrett, S., \& Stavins, R. (2003). Increasing participation and compliance in international climate change agreements. International Environmental Agreements, 3(4), 349-376.

Biancardi, M., \& Villani, G. (2010). International Environmental Agreements with asymmetric countries. Computational Economics, 36(1), 69-92.

Brown, G. M., \& Shogren, J. F. (1998). Economics of the endangered species act. The Journal of Economic Perspectives, 12(3), 3-20.

Carraro, C., \& Siniscalco, D. (1993). Strategies for the international protection of the environment. Journal of Public Economics, 52(3), 309-328.

Carraro, C., \& Siniscalco, D. (1998). International Institutions and Environmental Policy: International Environmental Agreements: Incentives and political economy. European Economic Review, 42(3-5), $561-572$. 
Chander, P. (2007). The $\gamma$-core and coalition formation. International Journal of Game Theory, 35(4), 539-556.

Chander, P., \& Tulkens, H. (1995). A core-theoretical solution for the design of cooperative agreements on transfrontier pollution. International Tax and Public Finance, 2(2), 279-293.

Chander, P., \& Tulkens, H. (1997). The core of an economy with multilateral environmental externalities. International Journal of Game Theory, 26(3), 379-401.

Chasek, P. S., Downie, D. L., \& Brown, J. (2013). Global environmental politics: Dilemmas in world politics (6th ed.). Boulder: Westview Press.

Chou, P. B., \& Sylla, C. (2008). The formation of an international environmental agreement as a two-stage exclusive cartel formation game with transferable utilities. International Environmental Agreements: Politics, Law and Economics, 8(4), 317-341.

D’Aspremont, C., Jacquemin, A., Gabszewicz, J. J., \& Weymark, J. A. (1983). On the stability of collusive price leadership. The Canadian Journal of Economics/Revue canadienne d'Economique, 16(1), 17-25. doi: $10.2307 / 134972$.

Elmqvist, T. (2012). Cities and biodiversity outlook-action and policy. Montreal: UN Secretariat of the Convention of Biological Diversity.

Eyckmans, J., \& Finus, M. (2006). Coalition formation in a global warming game: how the design of protocols affects the success of environmental treaty-making. Natural Resource Modeling, 19(3), 323-358. doi:10.1111/j.1939-7445.2006.tb00184.x.

Finus, M. (2001). Game theory and international environmental cooperation. Cheltenham: Edward Elgar.

Finus, M. (2008). Game theoretic research on the design of International Environmental Agreements: Insights, critical remarks and future challenges. International Review of Environmental and Resource Economics, 2, 29-67.

Finus, M., \& McGinty, M. (2015) The anti-paradox of cooperation: Diversity pays! Working Paper 40-15, Department of Economics, University of Bath.

Finus, M., \& Rübbelke, D. G. (2013). Public good provision and ancillary benefits: The case of climate agreements. Environmental \& Resource Economics, 56(2), 211-226. doi:10.1007/s10640-012-9570-6.

Fuentes-Albero, C., \& Rubio, S. J. (2010). Can international environmental cooperation be bought? European Journal of Operational Research, 202(1), 255-264.

Hein, L., van Koppen, K., de Groot, R. S., \& van Ierland, E. C. (2006). Spatial scales, stakeholders and the valuation of ecosystem services. Ecological Economics, 57(2), 209-228.

IUCN (2016). IUCN definitions glossary. Retrieved 25 May 2016. http://www.iucn.org/downloads/en_ iucn_glossary_definitions.pdf.

Kaul, I. (1999). Global public goods: International cooperation in the 21st century. New York: Oxford University Press.

Kumar, P. (2010). The economics of ecosystems and biodiversity: Ecological and economic foundations. Nairobi: UNEP/Earthprint.

Longo, A., Hoyos, D., \& Markandya, A. (2012). Willingness to pay for ancillary benefits of climate change mitigation. Environmental \& Resource Economics, 51(1), 119-140. doi:10.1007/s10640-011-9491-9.

McGinty, M. (2007). International Environmental Agreements among asymmetric nations. Oxford Economic Papers, 59(1), 45-62. doi:10.1093/oep/gpl028.

Mora, C., Tittensor, D. P., Adl, S., Simpson, A. G. B., \& Worm, B. (2011). How many species are there on Earth and in the ocean? PLoS Biology, 9(8), e1001127. doi:10.1371/journal.pbio.1001127.

Nagashima, M., Dellink, R., van Ierland, E. C., \& Weikard, H.-P. (2009). Stability of international climate coalitions-A comparison of transfer schemes. Ecological Economics, 68(5), 1476-1487.

Pavlova, Y., \& de Zeeuw, A. (2013). Asymmetries in International Environmental Agreements. Environment and Development Economics, 18(Special Issue 01), 51-68. doi:10.1017/S1355770X12000289.

Pearce, D. (2001). Policy framework for the ancillary benefits of climate change policies. In OECD (Ed.), Ancillary benefits and costs of greenhouse gas mitigation (pp. 517-560). Paris: OECD.

Perrings, C., \& Gadgil, M. (2003). Conserving biodiversity: reconciling local and global public benefits. In I. Kaul, P. Conceicao, K. Le Goulven, \& R. Mendoza (Eds.), Providing global public goods: managing globalization (pp. 532-555). Oxford: Oxford University Press.

Perrings, C., \& Halkos, G. (2012). Who cares about biodiversity? Optimal conservation and transboundary biodiversity externalities. Environmental \& Resource Economics, 52(4), 585-608. doi:10.1007/ s10640-012-9544-8.

Phelps, J., Webb, E. L., \& Adams, W. M. (2012). Biodiversity co-benefits of policies to reduce forest-carbon emissions. Nature Climate Change, 2(7), 7.

Pittel, K., \& Rübbelke, D. T. G. (2008). Climate policy and ancillary benefits: A survey and integration into the modelling of international negotiations on climate change. Ecological Economics, 68(1-2), 210-220. 
Pittel, K., \& Rübbelke, D. G. (2012). Transitions in the negotiations on climate change: From prisoner's dilemma to chicken and beyond. International Environmental Agreements: Politics, Law and Economics, 12(1), 23-39. doi:10.1007/s10784-010-9126-6.

Punt, M., Weikard, H.-P., Ierland, E., \& Stel, J. (2012). Large scale marine protected areas for biodiversity conservation along a linear gradient: Cooperation, strategic behavior or conservation autarky? Environmental \& Resource Economics, 53(2), 203-228. doi:10.1007/s10640-012-9559-1.

Rübbelke, D. T. G. (2006). Climate policy in developing countries and conditional transfers. Energy Policy, 34(13), 1600-1610.

Rubio, S. J., \& Ulph, A. (2006). Self-enforcing International Environmental Agreements revisited. Oxford Economic Papers, 58(2), 233-263. doi:10.1093/oep/gp1002.

Salles, J. M. (2011). Valuing biodiversity and ecosystem services: Why put economic values on Nature? Comptes Rendus Biologies, 334(5-6), 469-482.

Swanson, T., \& Groom, B. (2012). Regulating global biodiversity: What is the problem? Oxford Review of Economic Policy, 28(1), 114-138. doi:10.1093/oxrep/grs003.

Tulkens, H. (1998). Cooperation vs. free riding in international environmental affairs: Two approaches. In N. Hanley \& H. Folmer (Eds.), Game theory and the environment (pp. 30-44). Cheltenham: Edward Elgar.

UN. (1992). Convention on Biological Diversity. Rio de Janeiro: United Nations.

Weikard, H.-P. (2002). Diversity functions and the value of biodiversity. Land Economics, 78(1), $20-27$. doi:10.3368/le.78.1.20.

Weikard, H.-P. (2009). Cartel stability under an optimal sharing rule. The Manchester School, 77(5), 575-593. doi:10.1111/j.1467-9957.2009.02111.x.

Weikard, H.-P. (2011). Towards a global climate constitution. In M. Held, G. Kubon-Gilke, \& R. Sturn (Eds.), Jahrbuch Normative und institutionelle Grundfragen der Ökonomik (Vol. 9, pp. 89-106). Marburg: Metropolis.

Weitzman, M. L. (1998). The Noah's Ark problem. Econometrica, 66(6), 1279-1298. doi:10.2307/2999617.

Winands, S., Holm-Müller, K., \& Weikard, H.-P. (2013). The biodiversity conservation game with heterogeneous countries. Ecological Economics, 89, 14-23. doi:10.1016/j.ecolecon.2013.01.013.

World Bank. (2008). World development indicators. http://data.worldbank.org/data-catalog/worlddevelopment-indicators. Accessed 7 May 2015.

Young, O. R. (2011). Effectiveness of international environmental regimes: Existing knowledge, cuttingedge themes, and research strategies. Proceedings of the National Academy of Sciences, 108(50), 19853-19860. 